MADRASAH

Jurnal Pendidikan dan Pembelajaran Dasar

p ISSN: 1979-5599 | e ISSN: 2502-194X

Page | 97

\title{
Investigation of Primary School Teacher Readiness in Online Learning during the Covid-19 Pandemic
}

\section{Investigasi Kesiapan Guru Sekolah Dasar dalam Pembelajaran Online di Masa Pandemi Covid-19}

\author{
Esa Nur Wahyuni*1, Rahmat Aziz ${ }^{* 2}$, Wildana Wargadinata*3, Alfiana Yuli Efiyanti ${ }^{* 4}$ \\ Universitas Islam Negeri Maulana Malik Ibrahim Malang; Jalan Gajayana No 50 \\ Malang, telp Telp: +62-341 551-354 \\ 1esanw@uin-malang.ac.id, 2azira@uin-malang.ac.id, ${ }^{3}$ wildana@bsa.uin-malang.ac.id, \\ 4alfi_huda@pips.uin-malang.ac.id
}

\section{DOI: $10.18860 /$ mad.v13i2.11343}

Abstract. Changing the learning system during the pandemic period, offline to online, require teachers' readiness, not least elementary school teachers. The demands of technological mastery in learning and the characteristics of elementary school students who need direct guidance in learning become a problem for teachers. However, not all primary school teachers are ready for technology-based online learning. This study aims to investigate the readiness of elementary school teachers in online learning reviewed from three aspects, namely cognitive (knowledge and perception), affective (emotional condition), behavioral (skills). The research method uses mixed-method data collection techniques using questionnaires that are deepened by interviews. The study respondents were elementary school teachers in Tlekung village, Junrejo subdistrict, Batu City as many as 22 people. Data analysis using descriptive statistical analysis and qualitative analysis. The results showed that the average teacher has a lack of readiness to carry out online learning in general. In other words, the level of preparedness of primary school teachers to carry out online learning still needs to be improved, especially on the knowledge and skills factors. The results of this study provide an empiric foundation for education policymakers (government and schools) to facilitate elementary school teachers to develop online learning pedagogical skills.

Keywords. Online learning; Teacher readiness, Readiness Cognitive, Readiness Psychology, Readiness Behavior

Abstrak. Perubahan sistem pembelajaran selama masa pandemik dari offline ke online membutuhkan kesiapan guru, tidak terkecuali guru sekolah dasar. Tuntutan penguasaan teknologi dalam pembelajaran dan karakteristik siswa sekolah dasar yang membutuhkan bimbingan secara langsung dalam pembelajaran menjadi problema tersendiri bagi guru. Namun, tidak semua guru sekolah dasar siap dengan pembelajaran online berbasis teknologi. Penelitian ini bertujuan untuk menginvestigasi kesiapan guru-guru sekolah dasar dalam pembelajaran online ditinjau dari tiga aspek, yaitu kognitif (pengetahuan dan persepsi), afektif (kondisi emosional), bahavioral (keterampilan). Metode penelitian menggunakan mixed-method dengan teknik pengumpulan data menggunakan kuisioner yang diperdalam dengan wawancara. Responden penelitian adalah guru sekolah dasar di Desa Tlekung Kecamatan Junrejo Kota Batu sebanyak 22 orang. Analisa data menggunakan analisis statistik dekriptif dan

Vol. 13 No. 2 Juni 2021

Madrasah homepage: http://ejournal.uin-malang.ac.id/index.php/madrasah/index 
analisis kualitatif. Hasil penelitian menunjukkan secara umum, rata-rata guru memiliki tingkat kesiapan yang kurang untuk melaksanakan pembelajaran online. Dengan kata lain, tingkat kesiapan guru sekolah dasar untuk mampu melaksanakan pembelajaran online masih perlu ditingkatkan, terutama pada faktor pengetahuan dan keterampilan dengan memberikan pengalaman pelatihan pembelajaran online.

Kata Kunci. Pembelajaran Online; Kesiapan Guru; Kesiapan Kognitif; Kesiapan Psikologi; Kesiapan Perilaku

Received: 13-01-2021

Revised: 02-02-2021
Approved: 02-02-2021

Published: 30-03-2021

Copyright (C) Madrasah Jurnal Pendidikan dan Pembelajaran Dasar. All Right Reserved. This is an open access article under the CC BY-SA license

(Creative Commons Attribution-ShareAlike 4.0 International License.)

Correspondence Address: esanw@uin-malang.ac.id

\section{A. PENDAHULUAN}

Pembelajaran online sebagai sistem pembelajaran utama di masa pandemik, menjadi tantangan tersendiri bagi guru, khususnya guru sekolah dasar. Karakteristik siswa sekolah dasar yang masih dalam perkembangan awal membutuhkan bimbingan langsung dalam proses pembelajaran, sementara pembelajaran dilaksanakan secara virtual (Churiyah et al., 2020). Selain itu, tidak semua siswa sekolah dasar usia antara 612 tahun mampu mengoperasikan teknolgi untuk belajar (Purwanto et al., 2020; Fauzi \& Khusuma, 2020). Di sisi lain, hasil penelitian menunjukkan bahwa banyak guru sekolah dasar yang memiliki pengalaman terbatas dengan pembelajaran online (Lapada et al., 2020). Bagi guru sekolah dasar, mengajar online menjadi tantangan berat karena dengan segala keterbatasan, keterpaksaan, dan berbagai problematikanya, guru dituntut dapat menjalankan pembelajaran online secara maksimal dengan segala problematika yang menyertainya.

Studi yang ada tentang kesiapan guru sekolah dasar dalam pembelajaran online pada masa pandemi lebih berorientasi pada aspek eksternal guru. Misalnya, studi yang dilakukan oleh Fauzi dan Khusuma (2020). Studi tersebut meneliti tentang kesiapan guru dalam pembelajaran online dilihat dari faktor kesiapan fasilitas yang mendukung seperti ketersediaan kuota internet dan perangkat pembelajaran online (laptop dan handphone). Kedua, pembahasan kesiapan guru mengajar online dikaitkan dengan kesiapan orang tua dan guru (Aliyyah et al., 2020). Ketiga, kesiapan guru mengajar online dikaji dalam konteks kesiapan manajemen organisasi sekolah (Churiyah et al., 2020). Keempat, studi kesiapan guru untuk menguji keefektivan model treatment meningkatkan kompetensi guru mengajar online (Whalen, 2020). Keempat studi tersebut lebih menempatkan kesiapan guru dalam perpektif lingkungan di luar guru, sehingga belum diperoleh secara khusus gambaran kesiapan guru dari perspektif internal guru.

Studi ini bertujuan untuk melengkapi penelitian yang sudah ada, agar diperoleh gambaran yang lebih holistik tentang kesiapan mengajar online pada guru sekolah dasar di masa pandemi Covid-19. Studi ini lebih menekankan pembahasan pada bagaimana kesiapan guru dari aspek internal, yaitu kognitif, afektif, dan behavioral. Aspek kognitif meliputi keyakinan guru terhadap teknologi untuk kegiatan pembelajaran dan persepsi

Vol. 13 No. 2 Juni 2021

Madrasah homepage: http://ejournal.uin-malang.ac.id/index.php/madrasah/index 


\section{MADRASAH}

Jurnal Pendidikan dan Pembelajaran Dasar

p ISSN: 1979-5599 | e ISSN: 2502-194X

guru tentang efisiensi dan efektivitas pembelajaran online; aspek afektif terkait dengan kondisi psikologis guru selama pembelajaran online; dan aspek keterampilan membahas tentang pengalaman pendidikan atau pelatihan dan kemampuan mengaplikasikan dan mengelola teknologi dalam pembelajaran online. Ketiga aspek tersebut merupakan faktor penting bagi kepercayaan diri guru mengajar secara online di masa pandemi.

Dalam konteks pendidikan sekolah dasar di Indonesia, penelitian tentang kesiapan guru sekolah dasar menghadapi pembelajaran online di masa pandemi Covid19 masih terbatas. Di antara yang terbatas tersebut adalah penelitian STEM From Home: The Training For Primary School Teachers In Bandung Wetan As a Science Learning Alternative During The Covid-19 (Kurniawan et al., 2020). Penelitian yang dilakukan oleh Kurniawan dan kawan-kawan ini menggunakan pendekatan action research dengan memberikan pelatihan STEM untuk meningkatkan kesiapan guru melaksanakan pembelajaran online. Penelitian lainnya dilakukan oleh Novianti et al. (2020) tentang Readiness in Teaching Science: Early Childhood Education Teacher's Online Experience. Penelitian ini memfokuskan pada kajian kesiapan guru dalam aspek psikologis. Kemudian Aslan et al. (2020) melakukan penelitian tentang Teacher's Leadership Teaching Strategy Supporting Student Learning During The Covid-19 Disruption. Dalam penelitian tersebut Aslan dan kawan-kawan mengkaji kesiapan guru dalam melaksanakan manajemen pembelajaran online. Dari ketiga penelitian tersebut, penelitian tentang kesiapan guru mengajar online ini lebih memfokuskan kepada analisis faktor-faktor ketidaksiapan guru sekolah dasar dalam pembelajaran secara online selama masa pandemi. Tujuannya adalah memperoleh pemahaman tentang faktor-faktor yang mempengaruhi ketidaksiapan guru-guru dalam mengajar online.

Pembelajaran secara online menjadi pilihan mutlak bagi pelaksanaan pembelajaran di masa Covid-19. Pembelajaran online dalam masa pandemi merupakan pembelajaran jarak jauh dimana antara guru dan siswa terpisah oleh jarak (Santi, Gorghiu, and Pribeanu 2020; Wargadinata et al. 2020). Appana mendefinisikan pembelajaran online adalah pembelajaran formal di mana kegiatan dilaksanakan secara terpisah antara siswa dengan guru dan didukung dengan teknologi seperti laptop, komputer, televisi, email, dan handphone (Appana, 2008; Dhawan, 2020). Lebih lanjut Appana juga menyatakan bahwa pembelajaran online mengacu pada pengalaman belajar berbasis internet sebagai sarana utama untuk berkomunikasi dan presentasi (Appana, 2008). Dalam lingkungan pembelajaran online siswa dapat berada di mana saja (mandiri) dan berinteraksi dengan guru dan siswa lain (Singh \& Thurman, 2019). Dengan demikian dapat disimpulkan bahwa pembelajaran online merupakan pembelajaran berbasis internet yang dilakukan secara terpisah antara guru dengan siswa didukung teknologi komunikasi seperti laptop, komputer, televisi, email, dan handphone.

Kondisi keberadaan guru dan siswa yang terpisahkan jarak (tidak berada dalam satu ruangan serta berbasis internet) berimplikasi pada setidaknya ada tiga factor yang mempengaruhi keberhasilan pembelajaran online. Pertama, Keterlibatan siswa. Keterlibatan siswa yang dimaksud adalah mengacu pada kemauan siswa untuk meluangkan waktu dan upaya untuk mencurahkan pengalaman belajar (Ma et al., 2015). Kondisi jarak yang terpisah antara guru dan siswa memungkinkan rendahnya kontrol guru terhadap kehadiran siswa dalam kelas online, sehingga dibutuhkan

Vol. 13 No. 2 Juni 2021

Madrasah homepage: http://ejournal.uin-malang.ac.id/index.php/madrasah/index 
motivasi belajar agar siswa hadir dalam pembelajaran online (Henrie et al., 2015). Selain itu, proses pembelajaran online yang berlangsung tanpa kehadiran fisik dan komunikasi tidak bisa secara langsung, seringkali menjadi kendala terserapnya materi yang disampaikan oleh guru, khususnya pada siswa sekolah dasar. Oleh karena itu diperlukan strategi dan motivasi yang dapat mengarahkan perilaku belajar (Richardson \& Newby, 2006).

Kedua, peran guru dalam pembelajaran online. Guru ditantang bukan hanya mampu menyampaikan materi pelajaran saja tetapi juga memberikan bimbingan dan bantuan lebih besar serta mengintegrasikan sumber daya online untuk mengatur konten pembelajaran, menciptakan lingkungan pembelajaran online berkualitas tinggi, dan menekankan manajemen proses pembelajaran untuk merangsang motivasi belajar siswa dan meningkatkan efek pembelajaran (Ma et al., 2015; Baber, 2020). Pembelajaran online yang sukses bergantung pada motivasi yang dibuat dan struktur kursus, siswa dipersiapkan untuk belajar di ruang virtual, tetapi didukung dan dibimbing oleh guru (Weiner, 2003).

Ketiga, analisa big data dan monitoring keterlibatan siswa dalam pembelajaran online. Analisa berbasis data monitoring pelaksanaan pembelajaran online dapat membantu pengambil kebijakan (sekolah, pemerinta) untuk meningkatkan proses pengambilan keputusan, mengoptimalkan sumber daya, memantau kesulitan siswa pada waktu pembelajaran online dan menawarkan dukungan, serta mengubah mode pedagogi dan metode pengajaran. Dengan kata lain, tujuan analitik berbasis data pembelajaran bukan sekedar evaluasi. Tujuan yang lebih penting adalah untuk menyesuaikan konten, strategi dan aktivitas pembelajaran proses, dan segera memberikan umpan balik dan intervensi untuk meningkatkan kualitas pengajaran dan pembelajaran (Adedoyin \& Soykan, 2020).

Secara umum, kesiapan guru (teacher readiness) didefinisikan sebagai kemampuan seorang guru untuk memulai kegiatan mengajar (Sulaiman et al., 2017). Dalam konteks pembelajaran online, kesiapan guru dapat dipahami sebagai persepsi guru tentang kemampuan dan keterampilan yang diperlukan untuk mengintergrasikan teknologi ke dalam kegiatan mengajar di kelas (Inan \& Lowther, 2010). Kesiapan mengajar online juga dapat didefinisikan sebagai kesiapan fisik dan mental guru yang merujuk pada pengalaman dan kemampuan guru dalam megintegrasikan teknologi informasi dan komunikasi dalam pengalaman mengajar (Borotis et al., 2008). Dari beberapa definisi tentang kesiapan guru mengajar online dapat disimpulkan bahwa kesiapan guru mengajar online merupakan persepsi terhadap kesiapan dan kemampuan guru baik fisik maupun mental untuk mengintegrasikan teknologi informasi dan komunikasi dalam kegiatan mengajar.

Menurut Sulaiman et al.(2017), kesiapan guru mengajar dibagi dalam tiga faktor yaitu, kognitif, afektif, dan psikomotorik. Berdasarkan pada penjelasan Sulaiman et al, pembahasan tentang kesiapan guru mengajar online dalam studi ini juga difokuskan pada ketiga faktor tersebut. Pertama, kesiapan kognitif, kognitif merupakan proses berpikir yang terorganisir melibatkan pengambilan keputusan dan modifikasi kognitif. Kesiapan mengajar online secara kognitif adalah kemampuan guru untuk berpikir kritis dan kreatif merancang suatu konsep dalam memecahkan problem atau untuk melaksanakan tugas dalam pembelajaran online (Abdullah et al., 2017). Salah satu kemampuan penting dalam melaksanakan tugas mengajar adalah penguasaan guru tentang teknologi informasi dan komunikasi yang biasa disingkat dengan teknologi.

Vol. 13 No. 2 Juni 2021

Madrasah homepage: http://ejournal.uin-malang.ac.id/index.php/madrasah/index 
Pengetahuan teknologi ini sangat penting karena teknologi merupakan media utama dalam proses mengajar-belajar online. Guru yang memiliki pengetahuan teknologi akan dapat mengelola dan mengaplikasikan secara maksimal teknologi dalam proses pembelajaran (Champa, Rochsantiningsih, and Kristiana 2019; Spoel et al. 2020). Untuk mendapatkan pengetahuan dan pemahaman yang tepat guru dapat melalui pengalaman pelatihan dan pendidikan (Champa et al., 2019).

Kedua, faktor afektif, yaitu bagaimana emosi dapat mempengaruhi guru mencapai prestasi dalam melaksanakan tugasnya. Menurut Abdullah et al. (2017) aspek ini dibagi menjadi tiga bagian, (1) keadaan emosi positif guru dalam melaksanakan tugasnya, seperti tenang, bahagia, puas, dan senang; (2) keadaan afektif netral, yang mengacu pada seorang guru tidak merasakan emosi apapun pada waktu tertentu sesuai dengan situasi; (3) keadaan afektif negatif dimana guru berada dalam keadaan negatif seperti bosan, marah, gelisah atau kecewa. Ketika ada permasalahan dalam aspek afektif akan berdampak buruk terhadap performansi mengajar guru. Rendahnya aspek afektif guru menunjukkan guru mengalami kondisi emosi tidakbahagia, jenuh, dan stres, hal ini akan menyebabkan implementasi teknologi dalam pembelajaran menjadi tidak efektif. Berkenaan dengan hal tersebut, guru perlu membekali diri secara khusus dalam aspek keterampilan dan pengetahuan agar bisa menghadapi perubahan dan problema pembelajaran dari waktu ke waktu.

Faktor ketiga dari kesiapan guru mengajar online adalah kesiapan dari aspek perilaku atau psikomotorik. Kesiapan perilaku sangat erat kaitannya dengan reaktivitas afektif terhadap perubahan, dan perubahan yang terlihat pada perilaku. Sikap mengacu pada perilaku guru yang pada akhirnya akan membentuk kepribadiannya. Selain itu, kesiapan untuk berubah bergantung pada faktor internal dan eksternal, serta faktor pendorong. Karena perubahan itu dinamis dan subyektif, itu tidak boleh dilakukan secara tiba-tiba dan terburu-buru (Abdullah et al., 2017). Menurut Champa et al. (2019) kesiapan perilaku mengacu pada keterampilan yang digunakan dalam melakukan sesuatu. Guru yang terampil dan ahli dalam melakukan sesuatu yang baru dapat dikatakan memiliki tingkat kesiapan perilaku yang tinggi dan positif. Dalam pembelajaran online kesiapan psikomotorik atau perilaku ini ditunjukkan dengan kemampuan guru untuk mengoperasikan, mengelola, dan mengoptimalisasikan teknologi ke dalam kegiatan pembelajaran online.

\section{B. METODE PENELITIAN}

Penelitian ini menggabungkan dua pendekatan yaitu kuantitatif dan kualitatif (mixed method). Tujuannya adalah agar data kuantitatif (kuesioner) yang terkumpul dapat dipahami lebih mendalam dengan data kualitataif (hasil wawancara). Sebagaimana yang dikemukakan oleh Harrison, Reilly, and Creswell (2020) bahwa pendekatan mixed metode digunakan agar peneliti mendapatkan pemahaman yang mendalam terhadap data-data yang terkumpul. Peneliti mengumpulkan, menganalisa data, dan mengintegrasikan temuan-temuan, serta menarik kesimpulan dengan menggunakan pendekatan kuantitatif dan kualitatif.

Responden dalam penelitian ini adalah guru-guru sekolah dasar di Desa Tlekung Kecamatan Junrejo Kota Batu yang tengah mengikuti pelatihan penguatan pedagogi di masa pandemi Covid-19. Sebanyak 22 guru dengan karakteristik 
demografis (Tabel B.1) sebagai berikut; usia antara 25-55 tahun. Pendidikan rata-rata sarjana (S1) dan masa kerja antara 2-30 tahun.

Tabel B.1 Karakteristik Demografi Responden

\begin{tabular}{|l|l|c|}
\hline Karakteristik Demografi & \multicolumn{1}{|c|}{ Deskripsi } & Jumlah \\
\hline Pendidikan & Sarjana S1 & 22 \\
\hline \multirow{4}{*}{ Gender } & Laki-Laki & 8 \\
\cline { 2 - 3 } & Perempuan & 14 \\
\hline \multirow{5}{*}{ Usia } & 25-40 tahun & 11 \\
\cline { 2 - 3 } & $41-50$ tahun & 6 \\
\cline { 2 - 3 } & 51-60 tahun & 2 \\
\hline \multirow{5}{*}{ Pengalaman Mengajar } & $1-5$ tahun & 3 \\
\cline { 2 - 3 } & $6-10$ tahun & 7 \\
\cline { 2 - 3 } & $11-15$ tahun & 3 \\
\cline { 2 - 3 } & $16-20$ tahun & 2 \\
\cline { 2 - 3 } & $21-25$ tahun & 3 \\
\cline { 2 - 3 } & $26-30$ tahun & 2 \\
\cline { 2 - 3 } & $31-35$ tahun & 2 \\
\hline
\end{tabular}

Pengumpulan data dalam penelitian ini menggunakan kuisioner dengan tipe Skala Likert untuk data kuantitatif. Sedangkan data kualitatif menggunakan wawancara mendalam untuk lebih memahami fenomena kesiapan guru mengajar online di masa pandemik. Penelitian ini menggunakan kuisioner yang terdiri atas 6 pertanyaan yaitu; (1) Bagaimana keyakinan responden terhadap manfaat teknologi dalam pembelajaran?; (2) Bagaimana persepsi responden terhadap keefisienan dan keefektifan pembelajaran online?; (3) Apakah responden memiliki pengalaman mengikuti pelatihan pembelajaran berbasis teknologi?; (4) Bagaimana dampak pelatihan yang telah diikuti terhadap pembelajaran?; (5) Bagaimana keterampilan pengausaan responden terhadap teknologi untuk pembelajaran?; (6). Bagaimana kondisi emosional responden melaksanakan pembelajaran online di masa pandemi? Analisa data penelitian menggunakan statistic deskriptif untuk data kuantitaif dengan menggunakan SPSS versi 20, sedangkan data hasil wawancara menggunakan analisa kualitatitif dengan mengikuti tahapan persiapan dan pengorganisasian data, transkrip data, memahami data, memo data, pengkodean data, pembuatan kategori dan tema dari bagian kode yang mendasari, dan membuat proses analisis secara transparan.

\section{HASIL DAN PEMBAHASAN}

\section{Hasil}

Kesiapan guru mengajar online merupakan variabel penting yang menentukan keberhasilan pembelajaran di masa pandemi. Dalam studi ini, kesiapan guru mengajar online ditinjau dari 5 faktor, yaitu keyakinan, terhadap manfaat teknologi dalam pembelajaran, persepsi guru terhadap pembelajaran online, pengalaman guru mendapatkan pelatihan mengajar secara online, dan kemampuan guru untuk mengoperasikan, mengelola, dan memaksimalkan penggunaan teknologi dalam proses pembelajaran, serta kondisi psikologi ketika pembelajaran online. Kelima aspek tersebut menjadi indikator kesiapan guru mengajar secara online dalam studi ini.

\section{a. Kesiapan Guru Sekolah Dasar dalam Pembelajaran Online}


MADRASAH

Jurnal Pendidikan dan Pembelajaran Dasar

p ISSN: 1979-5599 | e ISSN: 2502-194X

Page | 103

Berdasarkan data yang terkumpul menunjukkan bahwa secara keseluruhan tingkat kesiapan guru (teacher readiness) berada pada tahap kurang siap (Tabel C.1).

Tabel C.1 Tingkat Kesiapan Guru Sekolah Dasar Dalam Pembelajaran Online

\begin{tabular}{|l|l|c|l|}
\hline \multicolumn{1}{|c|}{ Faktor } & \multicolumn{1}{|c|}{ Aspek } & Rata-rata & \multicolumn{1}{c|}{ Kriteria } \\
\hline \multirow{2}{*}{ Kognitif } & Keyakinan terhadap IT & 4,8 & Tinggi \\
\cline { 2 - 4 } & Persepsi pembelajaran online & 2,2 & Tidak efektif \\
\cline { 2 - 4 } & Pengalaman pelatihan & 1,8 & Kurang \\
\hline Afektif & Kondisi psikologis/emosi & 1,2 & Emosi negatif \\
\hline Psikomotorik/Behaviour & Keterampilan & 2,7 & $\begin{array}{l}\text { Kurang } \\
\text { Terampil }\end{array}$ \\
\hline \multicolumn{2}{|l|}{ Total Rata-rata } & 15,2 & Kurang Siap \\
\hline
\end{tabular}

Dari faktor kognitif pada aspek keyakinan terhadap manfaat IT, responden memiliki keyakinan yang tinggi terhadap manfaat IT $(4,8)$. Hal ini menunjukkan tidak ada problem dalam hal keyakinan responden terhadap manfaat IT. Sedangkan dari aspek persepsi terhadap pembelajaran online, rata-rata guru menyatakan pembelajaran online tidak efektif dan efisien $(2,2)$. Dari aspek pengalaman pelatihan, rata-rata guru kurang memiliki pengalaman pelatihan $(1,8)$. Dari faktor afektif, data penelitian menunjukkan bahwa rata-rata responden mengalami emosi negatif $(1,2)$, dan berkaitan dengan faktor psikomotorik/behaviour rata-rata guru kurang memiliki keterampilan mengelola pembelajaran online $(2,7)$.

b. Keyakinan guru terhadap manfaat teknologi informasi (Information Technologi) dalam pembelajaran.

Keyakinan responden terhadap Information Technologi (IT) dalam penelitian ini kepercayaan responden bahwa IT bermanfaat dalam pembelajaran online (Diagram 1). Sebanyak 19 guru (86\%) menyatakan bahwa IT sangat bermanfaat. Sedangkan 2 guru (9\%) menyatakan IT bermanfaat, dan sisanya 1 responden (5\%) menyatakan bahwa IT cukup bermanfaat. Berdasarkan data keyakinan responden ini dapat disimpulkan bahwa rata-rata responden memiliki keyakinan IT sangat bermanfaat bagi pembelajaran online. Atau dengan kata lain tidak ada responden yang menyanggah kebermanfaatan IT dalam pembelajaran online. Misalnya seorang responden (R1) menyatakan:

"Menurut saya teknologi informasi dan komunikasi sangat besar manfaatnya untuk pembelajaran"

Senada dengan pendapat R1 responden yang lain (R6) juga menyatakan:

"Sejujurnya saya sangat ingin menguasai teknologi pembelajaran yang canggih untuk mengajar, pasti anak-anak akan senang. Tapi sayangnya saya buta IT"

Diagram C.1 Keyakinan Responden terhadap Manfaat Teknologi dalam Pembelajaran

Vol. 13 No. 2 Juni 2021

Madrasah homepage: http://ejournal.uin-malang.ac.id/index.php/madrasah/index 


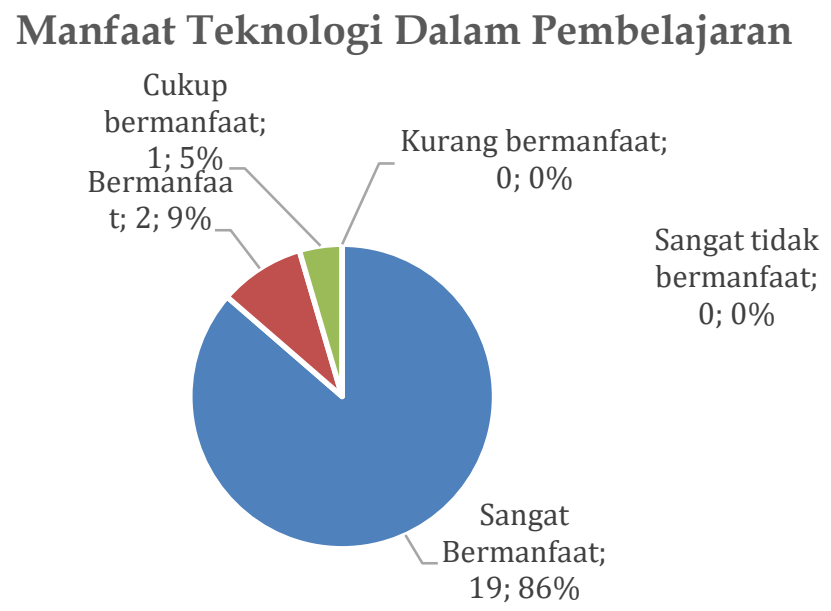

\section{c. Efektivitas dan Efisiensi Pembelajaran Online}

Faktor kedua dari kesiapan responden terhadap mengajar online adalah, persepsi responden terhadap keefisienan dan keefektifan pembelajaran online selama masa pandemi (diagram 2). Meski ada 5 responden (23\%) yang menyatakan bahwa pembelajaran online sangat efisien dan efektif, namun data menunjukkan bahwa ratarata responden $(77 \%)$ menyatakan pembelajaran online tidak efisien dan efektif. Secara rinci dapat dijelaskan, 14 responden (63\%) menyatakan bahwa pembelajaran online kurang efisien dan efektif; 3 responden (14\%) berpendapat pembelajaran online sangat tidak efisien dan efektif. Dengan demikian dapat dinyatakan bahwa menurut responden dalam penelitian ini, pembelajaran online tidak efisien dan efektif. Beberapa responden $(\mathrm{R} 1)$ dan $(\mathrm{R} 4)$ berpendapat;

"Memang produk IT sangat bermanfaat bagi pembelajaran, apalagi di masa pandemi ini. Namun menurut saya pembelajaran online kurang efektif terutama pada siswa sekolah dasar yang membutuhkan bimbingan secara langsung. Selain itu pembelajaran online sering kali membutuhkan waktu lebih lama."

Begitu juga R4 menyatakan;

"Banyak murid yang mengeluh pembelajaran online tidak nyaman. Tidak bisa langsung berinteraksi dengan guru sehingga lebih sulit memahami materi. Waktu belajar juga jadi lebih lama" 
MADRASAH

Jurnal Pendidikan dan Pembelajaran Dasar

p ISSN: 1979-5599 | e ISSN: 2502-194X

Page | 105

Diagram C.2 Persepsi Guru terhadap Efisiensi dan Efektivitas Pembelajaran Online

Keefisienan \& Keefektifan Pembelajaran Online

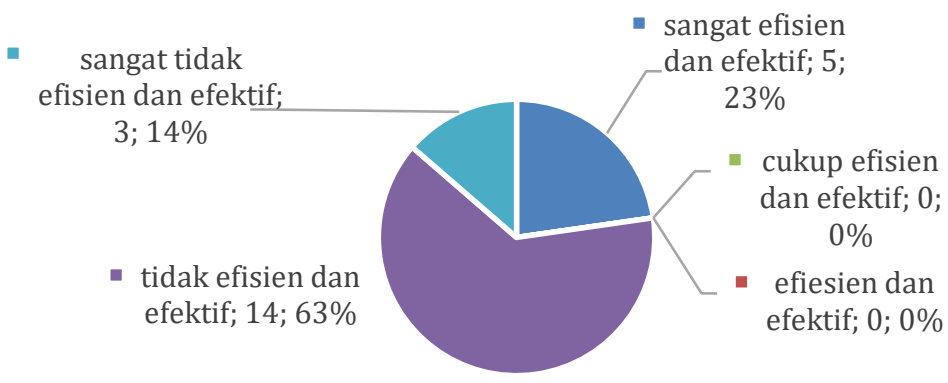

\section{d. Pengalaman Guru Mengikuti Pelatihan Pembelajaran Online}

Salah satu aspek yang menentukan kesiapan responden mengajar online di masa pandemi adalah pengalaman guru mengikuti pelatihan atau pendidikan pembelajaran online (Diagram 3). Data yang terkumpul menunjukkan sebagian besar 59\% (13 responden) memiliki pengalaman mengikuti pelatihan pembelajaran online, meskipun hanya sekali. Sedangkan sebanyak 4 responden $(18 \%)$ telah mengikuti pelatihan pembelajaran online lebih dari satu kali. Sedangkan 5 orang responden tidak pernah mengikuti pelatihan pembelajaran online baik secara inisiatif sendiri maupun pelatihan yang diselenggarakan atau difasilitasi oleh sekolah. Data ini menunjukkan bahwa ratarata responden yang menjadi responden dalam penelitian ini memiliki pengalaman mengikuti pelatihan pembelajaran online.

\section{Diagram C.3 Pengalaman Mengikuti Pelatihan Pembelajaran Online}

\section{Pengalaman Mengikuti Pelatihan}

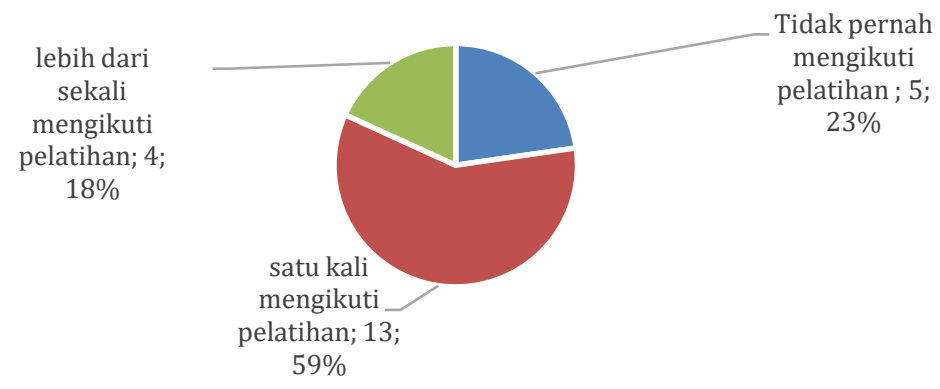

Meskipun rata-rata responden memiliki pengalaman mengikuti pelatihan menggunakan teknologi informasi dan komunikasi dalam pembelajaran, namun Sebagian besar responden tidak menerapkan hasil pelatihan tersebut dalam proses pembelajaran. Data yang terkumpul menunjukkan bahwa sebanyak, 18 responden (82\%) menyatakan tidak menerapkan hasil pelatihan pembelajaran online. Sedangkan 3 responden (14\%) menyatakan kadang-kadang menerapkan hasil pelatihan, dan sisanya sebanyak 1 responden (4\%) yang menyatakan menerapkan hasil pelatihan pembelajaran online. Data ini menunjukkan bahwa meskipun responden pernah mengikuti pelatihan pembelajaran online, namun mereka tidak menerapkan hasil 
pelatihan tersebut dalam proses pembelajaran. Seperti yang disampaikan oleh salah seorang responden (R15):

"saya punya pengalaman mengikuti pelatihan pengembangan media belajar online yang mengunakan teknologi. Namun, selama ini saya tidak pernah menerapkan hasil pelatihan dalam pembelajaran online, sehingga lupa lagi bagimana mengembangkan media belajar online".

Dengan demikian dapat dinyatakan bahwa penelitian tersebut tidak berdampak dalam pembelajaran.

Diagram C.4 Responden Menerapkan Hasil Pelatihan

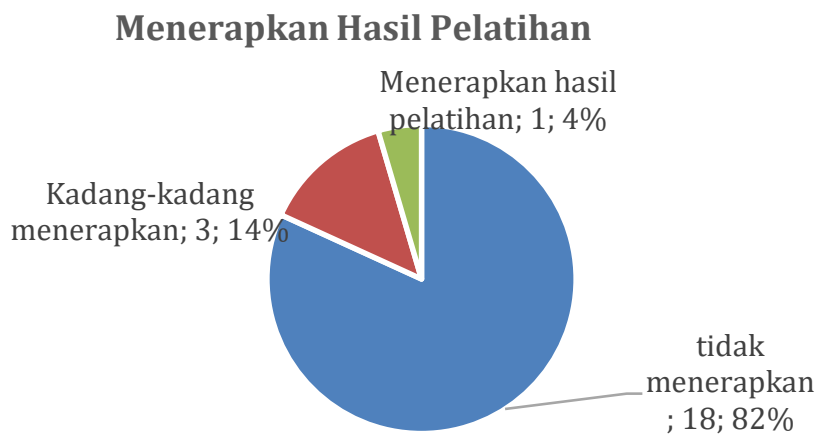

\section{e. Keterampilan Guru Mendayagunakan Teknologi dalam Pembelajaran Online}

Pembelajaran online berimplikasi pada tuntutan terhadap guru untuk memiliki keterampilan mendayagunakan teknologi dalam proses pembelajaran. Keterampilan pendayagunaan teknologi adalah kemampuan guru dalam mengaplikasikan, mengelola, dan memaksimalkan penggunaan teknologi dalam pembelajaran. Berdasarkan data yang diperoleh menunjukkan responden yang menguasai media pembelajaran online sebanyak 5 orang (23\%). Menurut responden, mereka menguasai lebih dari 2 media pembelajaran online dan bagaimana mengembangkan dan mengaplikasikan dalam pembelajaran. Seperti video animasi untuk pembelajaran, power point interaktif, dan media evaluasi online. Berikut salah satu responden menuturkan;

\section{"Alhamdulillah, saya menguasai lebih dari 2 media pembelajaran online, seperti video animasi, PPT, dan Quiznet utk evaluasi. Itu sangat membantu saya dalam pembelajaran di masa pandemi ini".}

Sedangkan sebanyak 14 responden (63\%) menyatakan cukup menguasai media pembelajaran online. responden tersebut dapat mengoperasikan beberapa media pembelajaran online namun tidak bisa mengembangkan media pembelajaran online. Seperti yang disampaikan responden (20);

"Saya bisa menggunakan beberapa media online yang sudah ada di internet, tetapi kalau untuk mengembangkan media online, Saya masih belum menguasai". 


\section{MADRASAH}

Jurnal Pendidikan dan Pembelajaran Dasar p ISSN: 1979-5599 | e ISSN: 2502-194X

Sisanya sebanyak 3 responden (14\%) menyatakan tidak menguasai penggunaan media pembelajaran online. Seperti yang disampaikan salah satu responden (R7);

"Usia saya sudah tua, bagaimana mengajar dengan media teknologi untuk pembelajaran online saya tidak bisa sama sekali. Biasanya saya minta bantuan anak atau orang yang bisa menggunakan media pembelajaran online di masa Covid ini".

Berdasarkan pada data yang terkumpul tentang keterampilan menguasai media pembelajaran online, dapat disimpulkan bahwa rata-rata responden kurang menguasai keterampilan mengaplikasikan media pembelajaran online dalam proses pembelajaran selama masa pandemi.

Diagram C.5 Keterampilan Guru Mengaplikasikan Media Pembelajaran Online Keterampilan Media Pembelajaran Online

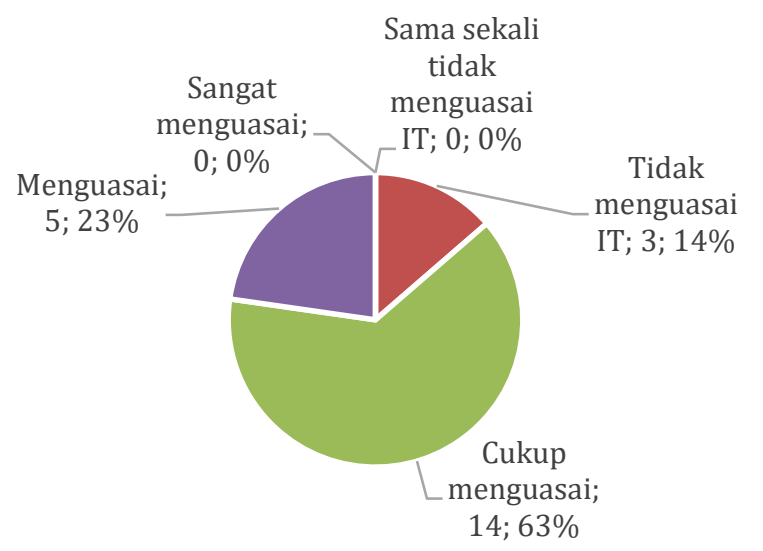

\section{f. Kesiapan Psikologis Guru Melaksanakan Pembelajaran Online}

Kesiapan psikologis merupakan kondisi emosional guru menghadapi pembelajaran online. Secara spesifik pertanyaan yang diajukan adalah apakah guru mengalami stres atau tertekan selama pembelajaran online di masa pandemi Covid-19. Berdasarkan hasil survei kepada guru-guru peserta pelatihan penguatan keterampilan pedagogi guru-guru sekolah dasar serta hasil wawancara (diagram 6) menunjukkan bahwa 55\% (12) responden merasa cukup stres selama pembelajaran online. Mereka kadang-kadang mengalami pusing, sakit perut, dan merasa tertekan. Seperti yang disampaikan oleh seorang responden (R11) yang melaporkan dirinya merasa sering pusing, sulit tidur, dan merasa tertekan memikirkan pembelajaran online di masa pandemi. Sebanyak 5 orang responden (23\%) merasakan dirinya stres dengan sistem pembelajaran online. Sebagai contoh pernyataan salah seorang dari kelima responden (R5) tersebut;

"Saya sering pusing setiap mengajar secara daring, kadang perut mual, dan sulit tidur bila memikirkan pembelajaran online. Saya khawatir anak-anak tidak dapat memahami materi yang saya sampaikan". 
Data juga menunjukkan ada 1 responden (4\%) yang merasakan sangat stres mengajar secara online. Kondisi sangat stres yang dirasakan tersebut sangat mengganggu kesehatannya dan motivasi dia mengajar. Pada sesi wawancara responden tersebut (R13) menyatakan;

"Sebagai guru, kondisi psikologis saya sangat merasa tertekan. Saya kurang bisa menguasai teknologi, selain itu saya tidak bisa lama-lama di depan laptop atau Hp. Saya juga resah kalau ada orang tua complain cara mengajar saya. Lama-lama saya merasa sangat jenuh, sering pusing dan mual-mual. Tapi bagaimana lagi?"

Tidak semua responden merasakan stres selama mengajar online, dari hasil survei terdapat 4 guru (18\%) yang menyatakan kondisi psikologis biasa saja atau netral. Responden yang mengalami emosi netral tersebut karena mereka menguasai beberapa media belajar online serta menganggap bahwa tidak terlalu menetapkan target pembelajaran ideal seperti pada saat pembelajaran luring. Seperti yang disampaikan oleh salah seorang responden (R7);

"secara psikologis saya biasa saja. Bagi saya pembelajaran online di masa pandemi adalah kondisi darurat. Sehingga saya tidak terlalu menuntut banyak kepada siswa, yang penting mereka sehat. Alahamdulillah saya menguasai teknologi sehingga bisa belajar lagi bagaimana pembelajaran online yang menyenangkan siswa".

Berdasarkan data yang diperoleh, dapat diketahui rata-rata responden mengalami kondisi psikologis cukup stres. Indikatornya antara lain, responden mengalami sakit kepala, mual, sakit perut, merasa cemas dengan ketercapaian pembelajaran, dan merasa jenuh selama proses pembelajaran online.

\section{Diagram C.6 Kondisi Psikologis Guru Selama Mengajar Online}

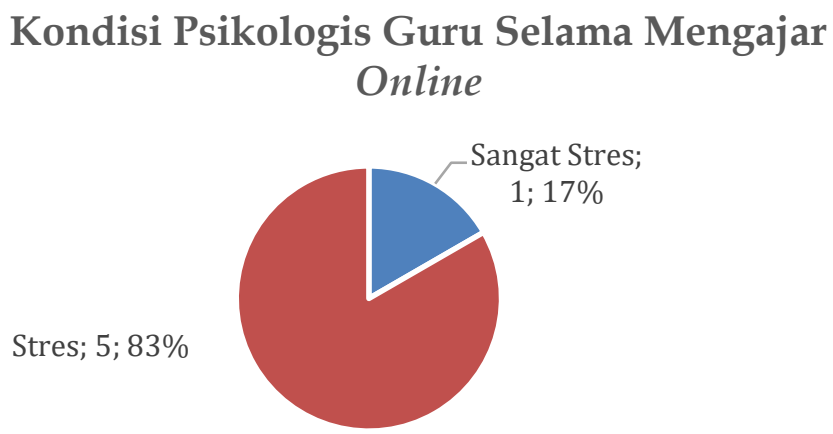

\section{Pembahasan}

Berdasarkan hasil analisis data, temuan penelitian ini menjelaskan lima aspek indicator kesiapan guru melaksanakan pembelajaran online di masa pandemi Covid-19. Pertama, tidak ada problem dengan keyakinan responden terhadap teknologi informasi dan komunikasi untuk pembelajaran. Rata-rata responden menyatakan bahwa teknologi sangat bermanfaat dalam pembelajaran, khususnya pada siswa sekolah dasar. Kedua, namun demikian terhadap pembelajaran online, rata-rata responden 


\section{MADRASAH}

Jurnal Pendidikan dan Pembelajaran Dasar

p ISSN: 1979-5599 | e ISSN: 2502-194X

berpendapat tidak efisien dan efektif karena ketercapaian pembelajaran rendah padahal waktu yang dibutuhkan lebih lama dan kegiatan belajar lebih banyak. Ketiga, dari segi pengalaman, rata-rata responden memiliki pengalaman mengikuti pelatihan pengembangan media berbasis teknologi untuk pembelajaran. Akan tetapi, hasil pelatihan tersebut tidak berdampak karena rata-rata responden tidak menerapkan hasil pelatihan ketika mengajar. Keempat, rata-rata responden kurang memiliki keterampilan untuk mengoperasikan media pembelajaran berbasis teknologi, tetapi tidak memiliki kemampuan mengembangkan media pembelajaran online. Kelima, secara psikologis rata-rata responden cukup stres menghadapai pembelajaran online di masa pandemi. Kondisi tersebut diindikasikan dengan adanya gejala sakit kepala, sakit perut, mual ketika melaksanakan pembelajaran online, cemas dengan ketercapaian pembelajaran, dan jenuh. Kelima kondisi responden tersebut dapat digunakan untuk memahami kesiapan responden menghadapi pembelajaran online di masa pandemi Covid-19.

Hasil temuan yang telah dipaparkan memberikan pemahaman empirik bahwa secara umum guru kurang siap dalam melaksanakan pembelajaran online. Walaupun guru-guru sekolah dasar yakin teknologi sangat bermanfaat bagi proses pembelajaran, namun ketika mereka dihadapkan dengan pilihan harus mengajar secara online (yang harus memanfaatkan teknologi), hampir semua guru menyatakan pembelajaran online tidak efektif dan efisien karena usaha dan waktu yang dibutuhkan lebih besar sedangkan hasilnya kurang maksimal. Guru juga masih kebingungan dan kesulitan untuk mengoperasikan, mengorganisasi, dan memaksimalkan media pembelajaran berbasis teknologi dalam pembelajaran online, meskipun mereka meiliki pengalaman tentang itu. Ketidaksiapan guru tersebut menjadi variabel yang berpengaruh bagi keberhasilan dan kualitas pembelajaran online.

Mengajar secara online selama pembelajaran dilaksanakan di rumah merupakan aktifitas pembelajaran yang harus dilaksanakan oleh guru. Untuk memahami bagaimana kegiatan pembelajaran tersebut dilaksanakan secara efektif, diperlukan identifikasi kesiapan mengajar online guru-guru (Hung, 2016). Secara empirik diketahui bahwa pada dasarnya guru memiliki keyakinan terhadap kebermanfaatan teknologi dalam pembelajaran. Keefisienan dan keefektifan penggunaan teknologi dalam pembelajaran tergantung pada pengetahuan, sikap, dan keterampilan guru menggunakan teknologi dalam pembelajaran (Thomas and Stratton 2006; Champa, Rochsantiningsih, and Kristiana 2019).

Ada ketidakkonsistenan dalam temuan ini antara keyakinan guru terhadap manfaat teknologi dalam pembelajaran dengan persepsi guru terhadap keefisienan dan keefektifan pembelajaran online selama masa pandemi. Dimana guru berpendapat pembelajaran online dengan media berbasis teknologi tidak efisien dan efektif. Berdasar hasil penelitian yang telah dilakukan oleh Rasmitadila et al. (2020) persepsi guru tersebut dipengaruhi oleh beberapa faktor, di antaranya pengalaman guru terhadap pembelajaran online yang kurang maksimal, hambatan dari sistem pendukung pembelajaran online, akses internet yang terbatas sampai dengan sikap orang tua dan siswa yang belum siap dengan belajar dari rumah.

Faktor lain yang turut memberi kontribusi ketidaksiapan guru mengajar secara online adalah kurangnya kemampuan dan keterampilan mengoperasikan, 
mengorganisasi, dan mengaplikasikan secara maksimal teknologi dalam pembelajaran pembelajaran online (Giovannella et al., 2020). Setidaknya ada tiga penyebab inkompetensi guru tersebut, yaitu (1) kurangnyapengalaman pelatihan atau pendidikan pengembangan dan pemanfaatan teknologi dalam pembelajaran. Faktor ini disinyalir menjadi penyebab inkompetensi guru mengaplikasikan teknologi pembelajaran ketika mengajar siswa (Kim 2020; Champa et al. 2019); (2) rendahnya inisiatif guru sekolah dasar menerapkan media berbasis teknologi dalam pembelajaran karena merasa cukup dengan metode mengajar secara langsung yang lebih tradisional (Churiyah et al., 2020); dan (3) sekolah yang kurang membudayakan pembelajaran berbasis teknologi, baik dari segi dukungan fasilitas maupun memotivasi guru untuk mengajar berbasis teknologi (Alea et al., 2020). Ketiga alasan tersebut perlu menjadi pertimbangan dalam meningkatkan kesiapan guru dalam mengajar online di masa pandemi Covid-19.

Berdasarkan pembahasan hasil penelitian terhadap kondisi empirik ketidaksiapan guru-guru sekolah dasar melaksanakan pembelajaran online, maka membuka potensi untuk dilakukan paling tidak ada tiga rencana tindakan. Pertama, meningkatkan pemahaman, kesadaran, dan penguasaan teknologi dalam pembelajaran bagi guru-guru melalui kegiatan-kegiatan in-service training. Kedua, mendorong dan memfasilitasi guru-guru sekolah dasar memiliki pengalaman melaksanakan pembelajaran online. Ketiga, memasukan penguasaan manajemen teknologi pembelajaran dalam kurikulum pendidikan guru. Ketiga rencana aksi tersebut dapat menjadi aksi dasar bagi pengembangan kualitas guru-guru sekolah dasar khususnya, dan pendidikan Indonesia pada umumnya yang tidak terbatas hanya pada masa pandemi.

\section{KESIMPULAN}

Penelitian ini menunjukkan bahwa pembelajaran online sebagai system pembelajaran yang dianggap ideal selama masa pandemi memunculkan banyak tantangan bagi berbagai pihak. Berdasarkan temuan dalam penelitian ini, keefisienan pembelajaran online salah satunya sangat tergantung pada kesiapan (readiness) guruguru. Di jenjang sekolah dasar, tantangan tersebut semakin besar karena karakteristik siswa sekolah dasar yang berada pada masa kanak-kanak dengan keterbatasan kemampuan berpikir logis dan abstrak, pertumbuhan fisik yang pesat, serta masa kritis membangun self-esteem (harga diri). Namun, kondisi real sebagian besar guru sekolah dasar memiliki kemampuan rendah untuk mengajar secara online. Oleh karena itu diperlukan tindakan untuk meningkatkan pemahaman, kesadaran, keterampilan agar guru siap mengajar online.

Penelitian ini menggunakan perspektif guru untuk menganalisis kesiapan guru mengajar online. Sehingga memungkinkan untuk memahami alasan mendasar ketidaksiapan guru dalam melaksanakan pembelajaran online. Selama ini, faktor internal guru kurang mendapatkan perhatian dalam pengembangan kualitas pendidikan, khususnya kapabilitas guru menguasai pembelajaran berbasis teknologi. Penelitian yang berpihak pada guru memungkin untuk mengakomodasi kebutuhankebutuhan guru untuk meningkatkan profesionalitas kinerjanya dalam memecahkan problem pendidikan.

Penelitian ini mengkaji hanya pada guru-guru sekolah dasar. Meskipun jenjang sekolah dasar memiliki problem yang lebih kompleks, namun penelitian tentang kesiapan guru-guru melaksanakan pembelajaran online di masa pandemi pada jenjang

Vol. 13 No. 2 Juni 2021

Madrasah homepage: http://ejournal.uin-malang.ac.id/index.php/madrasah/index 
sekolah menengah dan atas juga perlu dilakukan. Begitu juga penelitian kesiapan guruguru dalam pembelajaran online berdasarkan geografis, wilayah pedalaman, pedesaan, dan perkotaan perlu juga untuk diteliti.

\section{REFERENSI}

Abdullah, A. H., Hamzah, M. H., Hussin, R. H. S. R., Kohar, U. H. A., Rahman, S. N. S. A., \& Junaidi, J. (2017). Teachers' readiness in implementing science, technology, engineering and mathematics (STEM) education from the cognitive, affective and behavioural aspects. 2017 IEEE 6th International Conference on Teaching, Assessment, and Learning for Engineering (TALE), 6-12. https:/ / doi.org/10.1109/TALE.2017.8252295

Adedoyin, O. B., \& Soykan, E. (2020). Covid-19 pandemic and online learning: The challenges and opportunities. Interactive Learning Environments, 1-13.

Alea, L. A., Fabrea, M. F., Roldan, R. D. A., \& Farooqi, A. Z. (2020). Teachers' Covid-19 awareness, distance learning education experiences and perceptions towards institutional readiness and challenges. International Journal of Learning, Teaching and Educational Research, 19(6), 127-144.

Aliyyah, R. R., Rachmadtullah, R., Samsudin, A., Syaodih, E., Nurtanto, M., \& Tambunan, A. R. S. (2020). The Perceptions of Primary School Teachers of Online Learning during the COVID-19 Pandemic Period: A Case Study in Indonesia. Journal of Ethnic and Cultural Studies, 7(2), 90-109.

Appana, S. (2008). A review of benefits and limitations of online learning in the context of the student, the instructor and the tenured faculty. International Journal on ELearning, 7(1), 5-22.

Aslan, A., Silvia, S., Nugroho, B. S., Ramli, M., \& Rusiadi, R. (2020). Teacher's Leadership Teaching Strategy Supporting Student Learning During The Covid19 Disruption. Nidhomul Haq: Jurnal Manajemen Pendidikan Islam, 5(3), 321-333.

Baber, H. (2020). Determinants of students' perceived learning outcome and satisfaction in online learning during the pandemic of COVID-19. Journal of Education and ELearning Research, 7(3), 285-292.

Borotis, S., Zaharias, P., \& Poulymenakou, A. (2008). Critical success factors for elearning adoption. In Handbook of Research on Instructional Systems and Technology (pp. 498-513). IGI Global.

Champa, R., Rochsantiningsih, D., \& Kristiana, D. (2019). Teachers' Readiness Indicators on ICT Integration into their Teaching. Budapest International Research and Critics in Linguistics and Education (BirLE) Journal, 2, 195-203. https://doi.org/10.33258/ birle.v2i4.508

Churiyah, M., Sholikhan, S., Filianti, F., \& Sakdiyyah, D. A. (2020). Indonesia Education Readiness Conducting Distance Learning in Covid-19 Pandemic Situation. International Journal of Multicultural and Multireligious Understanding, 7(6), 491507.

Dhawan, S. (2020). Online Learning: A Panacea in the Time of COVID-19 Crisis. Journal of Educational Technology Systems, 49(1), 5-22. https:/ / doi.org/10.1177/0047239520934018 
Fauzi, I., \& Khusuma, I. H. S. (2020). Teachers' elementary school in online learning of COVID-19 pandemic conditions. Jurnal Iqra': Kajian Ilmu Pendidikan, 5(1), 58-70.

Giovannella, C., Passarelli, M., \& Persico, D. (2020). Measuring the effect of the Covid19 pandemic on the Italian Learning Ecosystems at the steady state: A school teachers' perspective. Interact. Des. Arch. J, 45, 1-9.

Harrison, R. L., Reilly, T. M., \& Creswell, J. W. (2020). Methodological Rigor in Mixed Methods: An Application in Management Studies. Journal of Mixed Methods Research, 1558689819900585.

Henrie, C. R., Halverson, L. R., \& Graham, C. R. (2015). Measuring student engagement in technology-mediated learning: A review. Computers $\mathcal{E}$ Education, 90, 36-53. https:/ / doi.org/10.1016/j.compedu.2015.09.005

Hung, M.-L. (2016). Teacher readiness for online learning: Scale development and teacher perceptions. Computers $\mathcal{E}$ Education, 94, 120-133. https:/ / doi.org/10.1016/j.compedu.2015.11.012

Inan, F. A., \& Lowther, D. L. (2010). Laptops in the K-12 classrooms: Exploring factors impacting instructional use. Computers $\mathcal{E}$ Education, 55(3), 937-944.

Kim, J. (2020). Learning and Teaching Online During Covid-19: Experiences of Student Teachers in an Early Childhood Education Practicum. International Journal of Early Childhood, 52(2), 145-158. https:/ / doi.org/10.1007/s13158-020-00272-6

Kurniawan, D. T., Yuniarti, Y., Sukardi, R. R., Yanthi, N., Yunansah, H., \& Maryanti, S. (2020). Stem From Home: The Training For Primary School Teachers In Bandung Wetan As a Science Learning Alternative During The Covid-19. PICS-J : Pasundan International Community Services Journal, 2(2), 105-116.

https://doi.org/10.23969/pics.v2i2.3328

Lapada, A. A., Miguel, F. F., Robledo, D. A. R., \& Alam, Z. F. (2020). Teachers' Covid-19 Awareness, Distance Learning Education Experiences and Perceptions towards Institutional Readiness and Challenges. International Journal of Learning, Teaching and Educational Research, 19(6), 127-144. https:// doi.org/10.26803/ijlter.19.6.8

Ma, J., Han, X., Yang, J., \& Cheng, J. (2015). Examining the necessary condition for engagement in an online learning environment based on learning analytics approach: The role of the instructor. The Internet and Higher Education, 24, 26-34. https://doi.org/10.1016/j.iheduc.2014.09.005

Novianti, R., Puspitasari, E., Solfiah, Y., Maria, I., \& Garzia, M. (2020). Readiness in Teaching Science: Early Childhood Education Teacher's Online Experience. Journal of Physics: Conference Series, 1655(1), 012065.

Purwanto, A., Pramono, R., Asbari, M., Hyun, C. C., Wijayanti, L. M., Putri, R. S., \& Santoso, priyono B. (2020). Studi Eksploratif Dampak Pandemi COVID-19 Terhadap Proses Pembelajaran Online di Sekolah Dasar. EduPsyCouns: Journal of Education, Psychology and Counseling, 2(1), 1-12.

Richardson, J. C., \& Newby, T. (2006). The role of students' cognitive engagement in online learning. American Journal of Distance Education, 20(1), 23-37.

Santi, E. A., Gorghiu, G., \& Pribeanu, C. (2020). Teachers' Perceived Self-Efficacy Concerning the Use of Mobile Technology in Education, Considering the "Working from Home" Format. Revista Romaneasca Pentru Educatie Multidimensionala, 12(1Sup2), 157-166.

https:/ / doi.org/10.18662/rrem/12.1sup2/259

Vol. 13 No. 2 Juni 2021

Madrasah homepage: http://ejournal.uin-malang.ac.id/index.php/madrasah/index 
Singh, V., \& Thurman, A. (2019). How many ways can we define online learning? A systematic literature review of definitions of online learning (1988-2018). American Journal of Distance Education, 33(4), 289-306.

Sulaiman, T., Hamzah, S. N., \& Rahim, S. S. A. (2017). The Relationship between Readiness and Teachers' Competency towards Creativity in Teaching among Trainee Teachers. International Journal of Social Science and Humanity, 7(8), 4.

Thomas, A., \& Stratton, G. (2006). What we are really doing with ICT in physical education: A national audit of equipment, use, teacher attitudes, support, and training. British Journal of Educational Technology, 37(4), 617-632.

van der Spoel, I., Noroozi, O., Schuurink, E., \& van Ginkel, S. (2020). Teachers' online teaching expectations and experiences during the Covid19-pandemic in the Netherlands. European Journal of Teacher Education, 43(4), 623-638.

Wargadinata, W., Maimunah, I., Dewi, E., \& Rofiq, Z. (2020). Student's Responses on Learning in the Early COVID-19 Pandemic. Tadris: Jurnal Keguruan Dan Ilmu Tarbiyah, 5(1), 141-153. https://doi.org/10.24042/tadris.v5i1.6153

Weiner, C. (2003). Key ingredients to online learning: Adolescent students study in cyberspace-the nature of the study. International Journal on E-Learning, 2(3), 4450.

Whalen, J. (2020). Should teachers be trained in emergency remote teaching? Lessons learned from the COVID-19 pandemic. Journal of Technology and Teacher Education, 28(2), 189-199. 